\title{
Experiência Conjugal de Casal Cis-trans: Contribuições ao Estudo da Transconjugalidade
}

\author{
Vinícius Alexandre ${ }^{1}$ \\ ${ }^{1}$ Universidade de São Paulo, São Paulo, Brasil
}

\author{
Manoel Antônio dos Santos ${ }^{1}$ \\ ${ }^{1}$ Universidade de São Paulo, São Paulo, Brasil
}

Resumo: Na contemporaneidade, estudos voltados à temática da transexualidade têm ganhado progressivo destaque na agenda dos pesquisadores de diferentes áreas, como Psicologia, Medicina, Direito e Ciências Sociais. No entanto, ainda é esparsa a literatura dedicada a investigar a vivência afetiva e relacionamentos conjugais em pessoas trans. Esta lacuna é expressão da condição discriminatória e da abjeção a que as subjetividades trans estão submetidas. Considerando essa insuficiência, este estudo buscou desvelar os sentidos atribuídos à conjugalidade por um casal cis-trans. O método empregado foi o Estudo de Caso Único, elaborado com base em entrevista narrativa episódica. Os resultados obtidos foram analisados adotando-se a perspectiva Queer como enquadramento teórico. A análise aponta que a relação conjugal entre pessoas trans e cisgênero é marcada pelo encontro de duas histórias de vida distintas no que diz respeito à aceitação social e passabilidade, mas que em algum momento se interseccionam por meio da formação de laço afetivo. Relacionar-se fora das normas culturalmente atribuídas aos gêneros e sexualidades envolve uma série de riscos e barreiras, uma vez que a vida e o corpo do indivíduo se tornam alvos de exclusão, violação de direitos e tentativas de eliminação pelos efeitos da necropolítica. Ao mesmo tempo, amar para além das normas também pode implicar em um processo libertário ampliado, uma vez que algumas das amarras da cultura heteronormativa se afrouxam. Quando existe apoio familiar e de amigos, o relacionamento tende a munir-se de recursos que favorecem o empoderamento e enfrentamento de situações adversas e potencialmente ameaçadoras, que poderiam resultar na dissolução da união.

Palavras-chave: Transexualidade, Conjugalidade, Teoria queer. 


\title{
Marital Experience of a Cisgender-Transsexual Couple: Contributions to the Study of Transconjugality
}

\begin{abstract}
At the present time, studies focusing on the subject of transsexuality have gradually gained prominence in the agenda of researchers from different areas, such as psychology, medicine, law and social sciences. However, the literature dedicated to investigating affective experience and marital relationshipsintranssexual peopleisstillsparse.Thisgapisan expression of thediscriminatorycondition and the abjection to which transsexual subjectivities are subjected. Considering this insufficiency, this study sought to unveil the meanings attributed to conjugality by a cisgender-transsexual couple. The method used was the Single Case Study, based on an episodic narrative interview. The results obtained were analyzed by adopting the Queer perspective as a theoretical framework. The analysis points out that the conjugal relationship between transsexual and cisgender people is marked by the encounter of two distinct life histories regarding social acceptance and passability, but at some point intersecting each other through the formation of an affective bond. Relating outside the culturally attributed norms to gender and sexuality involves a number of risks and barriers, since the individual's life and body become targets of exclusion, violation of rights, and attempts at elimination through the effects of necropolitics. At the same time, to love beyond the norms can also imply in an enlarged libertarian process, since some of the strings of the heteronormative culture loosen up. When there is family and friends support, the relationship tends to provide resources that favor the confrontation of adverse and potentially threatening situations that could result in the dissolution of the union.
\end{abstract}

Keywords: Transsexuality, Conjugality, Queer theory.

\section{Experiencia Marital de la Pareja Cisgénero-Transexual: Contribuciones al Estudio de la Transconjugalidad}

Resumen: En la actualidad, los estudios que se centran en el tema de la transexualidad han ganado gradualmente protagonismo en la agenda de investigadores de diferentes áreas, como la psicología, la medicina, el derecho y las ciencias sociales. Sin embargo, la literatura dedicada a investigar la experiencia afectiva y las relaciones maritales en personas transexuales todavía es escasa. Esta brecha es una expresión de la condición discriminatoria y la abyección a la que están sometidas las subjetividades transexuales. Considerando esta insuficiencia, este estudio buscó revelar los significados atribuidos a la conyugalidad por una pareja cisgénero-transexual. El método utilizado fue el Estudio de Caso Único, basado en una entrevista narrativa episódica. Los resultados obtenidos se analizaron adoptando la perspectiva Queer como marco teórico. El análisis señala que la relación conyugal entre las personas transexuales y cisgénero está marcada por el encuentro de dos historias de vida distintas con respecto a la aceptación social y la transitabilidad, pero en algún punto se cruzan entre sí a través de la formación de un vínculo afectivo. Relacionarse fuera de las normas atribuidas culturalmente al género y la sexualidad implica una serie de riesgos y barreras, ya que la vida y el cuerpo del individuo se convierte en objecto de exclusión, violación de derechos e intentos de eliminación a través de los efectos de la necropolítica. Al mismo tiempo, amar más allá de las normas también puede implicar un proceso libertario ampliado, ya que algunas de las cadenas de la cultura heteronormativa se relajan. Cuando hay apoyo de familiares y amigos, la relación tiende a proporcionar recursos que favorecen la confrontación de situaciones adversas y potencialmente amenazadoras que podrían resultar en la disolución de la unión.

Palabras clave: Transexualidad, Conyugalidad, Teoría queer. 


\section{Introdução}

O tema da(s) conjugalidade(s) tem sido alvo de debates contemporâneos no âmbito das ciências humanas e sociais, à medida que os relacionamentos afetivos e o casamento, na condição de uma instituição basilar da organização social, tiveram seus significados transformados nas últimas décadas (Oltramani, 2009). A despeito dos questionamentos, observa-se que permanece o desejo das pessoas em se relacionarem de forma íntima e amorosa, bem como a persistência da instituição do casamento e da valorização da fidelidade (Jablonski, 2007; Lipovetsky, 2004; Mosmann, Lomando, \& Wagner, 2010; Scorsolini-Comin, \& Santos, 2012). Uma demonstração clara dessa realidade pode ser observada no aumento significativo do número de casamentos no Brasil, ainda que este venha acompanhado pelo incremento dos índices de divórcios (Silva, Scorsolini-Comin, \& Santos, 2017).

Jablonski (2007) argumenta que a busca pela felicidade e pelo amor, a partir do estreitamento dos laços afetivos e da conjugalidade, constituem-se como um ideal da pós-modernidade valorizado e buscado pelos jovens. A união não anula as individualidades identitárias dos membros do casal e, ao mesmo tempo, faz emergir uma terceira identidade, denominada por Féres-Carneiro (1998) de "identidade conjugal", a qual geralmente é referida na literatura sobre casamento e terapia de casal como conjugalidade.

Atualmente, é comum coexistirem empiricamente múltiplas formas de vivência da conjugalidade “[...] desde o modelo tradicional até o 'ficar', a coabitação na casa dos pais, a união estável, o estar casado, mas viver em casas separadas, os casamentos consecutivos, as uniões homoafetivas, o 'poliamor', os casamentos 'abertos' e tantos outros contratos de relacionamentos amorosos" (Zordan, \& Wagner, 2009, p. 95). A exemplo dessa multiplicidade dos modos de vivenciar a conjugalidade, os casais homoafetivos têm tido especial destaque na agenda de pesquisas que versam sobre a qualidade e satisfação no interior dos relacionamentos. Mosmann, Lomando e Wagner (2010), ao compararem a qualidade dos relacionamentos de casais de gays e lésbicas com casais heterossexuais, no que que tange aos níveis de coesão e adaptabilidade conjugal (sendo a coesão referente à medida geral de aproximação afetiva na relação do casal e a adaptabilidade conjugal a capacidade do casal em se reestruturar à medida que estressores relacionais ou ambientais se façam presentes), concluíram que os níveis de coesão e adaptabilidade conjugal foram maiores para os casais homossexuais quando comparados aos casais heterossexuais; sendo que todos os casais heterossexuais estudados tinham suas relações tuteladas pelo Estado. Estes resultados corroboram outros estudos de pesquisa, como os obtidos por Zacks, Green e Marrow (1988), que compararam o nível de qualidade relacional entre casais de lésbicas e casais heterossexuais, obtendo como resultado um maior nível de coesão, adaptabilidade e satisfação para os casais lésbicos.

Já no que tange às relações conjugais cis-trans, circunstância na qual um homem ou mulher cisgênero se relaciona com um homem ou mulher trans, Erich, Tittsworth, Dykes e Cabuses (2008) argumentam que a literatura ainda negligencia o estudo sistemático dos relacionamentos trans, sendo que a maior parte dos raros estudos que se ocupam dessa temática não analisa o bem-estar relacional dos casais, nem se preocupa em associar fatores como satisfação com a vida e autoestima com a qualidade das relações familiares. Tal negligência nada mais é do que uma extensão da condição discriminatória e do lugar de abjeção atribuído às subjetividades trans.

Pesquisas que tenham como grupo-alvo homens e mulheres trans (indivíduos que se identificam com o gênero oposto ao que lhes foi designado socialmente) tem ganhado impulso e visibilidade crescentes, angariando cada vez mais interesse nos meios acadêmicos nas últimas décadas (Melo, 2016). Entre as diferentes áreas de conhecimento que voltaram suas atenções para essa população, destacam-se a Psicologia, a Psiquiatria, a Medicina, o Direito e a Terapia Ocupacional. A área médica, no entanto, foi pioneira na busca pela compreensão da natureza e das características singulares da chamada "transexualidade", tendo obtido alguns resultados e proferido conclusões que não estão necessariamente alinhadas com o respeito à condição humana das pessoas trans. Bento e Pelúcio (2012) referem que as ciências médicas, ao compreenderem a abjeção pelo órgão sexual como o fator principal da manifestação da transexualidade, tem desenvolvido suas pesquisas em torno da compreensão da transexualidade como uma condição patológica a ser tratada (devido a essa concepção patologizante ela era, inicialmente, denominada de transexualismo), sendo o "tratamento" restrito basicamente ao corpo, como se intervenções cirúrgicas e hormonais fossem um destino inevitável e desfecho inexorável para toda 
pessoa trans (Galli, Vieira, Giami, \& Santos, 2013). Bento e Pelúcio (2012) pontuam que essa perspectiva patologizante se reflete nas avaliações e diagnósticos clínicos que ainda hoje são perpetrados.

A nomeação de homens e mulheres como pessoas trans envolve uma série de discussões, tanto pela diversidade dos critérios diagnósticos presentes em diferentes publicações de referência (Associação Americana de Psiquiatria, 2014; Organização Mundial da Saúde, 1993; Santos et al., 2019), como pelo fato de que essa "necessidade" quase compulsiva de diagnosticar as expressões de gênero está na contramão de movimentos sociais que defendem a despatologização da transexualidade, reivindicando inclusive a substituição do termo médico "transexual" por "trans" (Santos, 2019).

$\mathrm{O}$ relacionamento conjugal entre homens e mulheres trans e seus parceiros cisgênero tem sido pouco investigado. A partir de uma revisão da literatura por nós empreendida para fundamentar o presente estudo, e que abrangeu as produções acadêmicas que se dedicaram a compreender as especificidades do funcionamento das relações entre casais cis-trans, foi confirmada a escassez significativa de pesquisas nesse campo, especialmente na literatura brasileira. Kulick (2008) argumenta que existe uma tendência, nos estudos com trans e travestis, em diminuir a importância da experiência subjetiva dessas pessoas no campo dos relacionamentos amorosos, em detrimento de outras variáveis enfatizadas pelos pesquisadores. A exemplo disso, o autor pontua que a maioria dos estudos sobre prostituição enfatiza a relação da travesti com sua clientela, como se essa relação fosse a mais importante em suas vidas, sendo que, na verdade, seus(suas) namorados(as), parceiros(as) íntimos(as) ou cônjuges é que ocupam uma posição central e constante.

Lomando e Nardi (2013) referem que buscar compreender as experiências conjugais da população trans é de extrema importância, uma vez que essa busca permite explorar o quanto a situação de conflito com as normas heteronormativas (normas que coercitivamente imputam a ideia de que um casal cisgênero heterossexual é a única configuração conjugal válida) é capaz de produzir algum efeito em seus relacionamentos.

Bischof, Warnaar, Baraja e Dhaliwal (2011), ao analisarem relatos de casos clínicos de mulheres cisgênero que se relacionavam com mulheres transexu- ais, concluíram que o relacionamento da maioria dos casais foi afetado pela transição de gênero das parceiras trans, de maneira que as relações sexuais na maior parte das díades diminuíram em frequência ou foram totalmente abolidas, resultando em relacionamentos celibatários. A opção pelo celibato partiu fundamentalmente das parceiras cisgênero, havendo aquelas que argumentaram que uma relação sexual seria incompatível com as condições atuais do corpo dos parceiros (agora parceiras) e que quebraria o amor compartilhado por eles(as) em nível "espiritual".

Estudando a vivência conjugal de mulheres que se relacionavam ou já haviam se relacionado com homens transexuais, Brown (2010) obteve resultados qualitativamente diferentes no campo das relações sexuais. A maioria das participantes que haviam vivenciado o período de transição de gênero de seus parceiros relatou que, passado o choque e apreensão do início da transição de gênero, as relações e práticas sexuais se tornaram mais variadas e satisfatórias para ambas as partes, à medida que o processo avançava para estágios nos quais as características fenotípicas masculinas de seus parceiros se faziam mais evidentes. A vida sexual dos casais passou a ser marcada pela renomeação das partes do corpo e pela introdução de atividades sexuais particulares, nas quais se incluía o uso de objetos eróticos.

Ao se compararem os resultados dos estudos de Bischof et al. (2011) e Brown (2010), pode-se supor que a diferença na forma como as relações sexuais foram aceitas pelas mulheres cisgênero após a transição de gênero dos(as) parceiros(as) esteja atrelada à diferença fundamental de que as mulheres que mostraram melhor aceitação se relacionavam com homens transexuais (anteriormente vistos como mulheres cisgênero) e as que se relacionaram pior se relacionavam com mulheres transexuais (anteriormente homens transexuais). Esse dado, reforçado pelo estudo de Kins, Hoebeke, Heylens, Rubers e Cuypera (2008), que revelou não haver diferenças significativas na satisfação relacional entre casais cisgênero e casais formados por uma mulher cisgênero e um homem transexual, leva a crer que a aproximação dos casais na direção de um padrão heterossexual, no primeiro caso, possa estar associada com a experiência de satisfação relacional e sexual, ao passo que, no segundo caso, observou-se a construção de um casal considerado homossexual, que está em desacordo com a cultura heteronormativa (Warner, 1993). 
No entanto, deve-se salientar que, embora o afastamento em relação ao modelo conjugal heteronormativo pareça reverberar na esfera afetiva, social e familiar, Alegría (2012) e Bischof et al. (2011) apontam que é possível que casais transexuais, inclusive homossexuais, objetos de seu estudo, encontrem um ponto de estabilidade e felicidade, inclusive sexual, por meio da transformação de seus relacionamentos e da descoberta de novas formas de amar e expressar amor e sexualidade.

Considerando as lacunas da literatura, este estudo buscou desvelar os sentidos atribuídos à conjugalidade por um casal cis-trans.

\section{Método}

Foi de interesse deste estudo vislumbrar as singularidades, alegrias e sofrimentos experienciados no interior de uma relação cis-trans, levando em conta tanto os fatores culturais e sociais de coerção das normas de gênero, quanto as experiências intrapsíquicas que são particulares a quaisquer seres humanos e que se traduzem na forma como os relacionamentos são vividos em determinado horizonte histórico e social.

Para alcançar o objetivo proposto, optou-se pelo uso do método de Estudo de Caso Único que, segundo Yin (2013), tem sido uma estratégia de investigação valorizada no âmbito das ciências sociais ao longo do tempo. O Estudo de Caso se mostra um método valioso de investigação por permitir que os indivíduos pesquisados possam ter seus comportamentos registrados no momento em que eles se encontram envolvidos no próprio fenômeno investigado. Além disso, o Estudo de Caso comtempla uma série de oportunidades de estudo, compreensão e transformação da realidade social (Serrano, 2004).

$\mathrm{Na}$ presente pesquisa, os protagonistas são nomeados como Jonas, um homem trans, branco, 30 anos, atualmente desempregado, e sua parceira, Ângela, uma mulher cisgênero, negra, 31 anos, secretária em um escritório de advocacia. Ambos residem em uma cidade no interior de São Paulo e dividem a moradia (uma casa alugada) com um amigo.

O primeiro convite para participação no estudo foi endereçado a Jonas por meio de uma rede social. Um dos pesquisadores já conhecia Jonas há algum tempo, uma vez que ele já havia participado de outra pesquisa conduzida por ele e que tinha como público-alvo a população trans. Após conversar com sua parceira e ela aquiescer com o convite, Jonas se dispôs a receber o pesquisador em sua casa para ser entrevistado junto com sua companheira.

O método de Estudo de Caso possibilita o uso de múltiplas fontes de obtenção de dados, que podem ser utilizadas para investigar o fenômeno de maneira mais completa, como entrevistas, observação comportamental e do ambiente escolhido para a realização da entrevista, além de pesquisa documental (Chetty, 1996). Dessa maneira, o pesquisador pôde optar conjuntamente pelo uso de uma entrevista com uso de roteiro semiestruturado, observação tanto da dinâmica do casal durante a entrevista quanto da casa onde o encontro ocorreu (ambas registradas por meio de anotações do diário de campo) e da observação de um álbum de fotografias, a convite e por iniciativa do próprio casal.

A entrevista foi audiogravada e conduzida simultaneamente com os dois membros do casal, tendo em vista que se pretendia encorajar relatos associados às particularidades da relação conjugal, associados à observação atenta da dinâmica comportamental estabelecida entre os cônjuges. Optou-se pela utilização de entrevistas narrativas episódicas. O uso desse tipo específico de técnica de entrevista é consistente com os objetivos do estudo, que pressupõem o desejo de possibilitar uma atmosfera permissiva para que os participantes se sentissem confortáveis para expressarem livremente suas vivências, sentimentos e significações, de maneira que se esperava que tal abordagem resultasse em uma quantidade densa e diversificada de dados (Muylaert, Sarubim, Gallo, Rolim Neto, \& Reis, 2014).

A entrevista foi realizada em um encontro único, com duração de uma hora e 42 minutos. O conteúdo da entrevista foi posteriormente transcrito na íntegra e analisado segundo os passos da análise dedutiva proposta por Braun e Clark (2006). Os resultados serão apresentados de maneira narrativa, tendo em vista a preocupação com descrever, ilustrar e analisar as situações estudadas, tal como propõe Serrano (2004) e Gomez, Flores \& Jimenez (1999). Como o estudo em questão abordou uma unidade particular de um determinado recorte social, não é possível fazer generalizações estatísticas. Dessa maneira, empregou-se uma generalização analítica, tal como proposta por Yin (2013), que tem por objetivo generalizar as proposições do modelo teórico encontrado em vez de generalizar as vivências dos entrevistados para toda a população a qual eles pertencem. Uma generalização 
grosseira que, no caso, terminaria por invisibilizar as reais vicissitudes da configuração conjugal estudada e também reforçaria estereótipos contra uma população que já é socialmente estigmatizada.

Os estudos em gênero e sexualidade que apresentam a perspectiva queer como referencial teórico foram escolhidos para alicerçar a análise dos resultados e contribuir com a construção de proposições teóricas. A escolha justifica-se pela possibilidade que os estudos queer abrem de desconstruir os coercitivos padrões corporais, de comportamento, de pensamento e de existir que marcam a experiência sexual e de gênero na sociedade contemporânea e que muitas vezes são reproduzidos inclusive na literatura científica. Analisar os dados buscando manter uma distância crítica em relação aos padrões estereotipados vigentes e aos vieses moralistas é uma forma não só de garantir uma análise mais íntegra do material de pesquisa, como também responde ao compromisso ético da ciência psicológica de não propagar instrumentos de coerção que geram sofrimento físico e mental para a população trans.

Este estudo seguiu os princípios éticos estabelecidos pela legislação vigente (Resolução ${ }^{\circ}{ }^{466 / 2012)}$ para pesquisas que envolvem seres humanos. $\mathrm{O}$ projeto foi aprovado pelo Comitê de Ética em Pesquisa da Faculdade de Filosofia, Ciências e Letras de Ribeirão Preto da Universidade de São Paulo, protocolo CAEE CEP/FFCLRRP-USP no 85418318.3.0000.5407.

\section{Resultados e discussão}

\section{Vidas pregressas - Jonas}

Jonas percorreu uma trajetória de vida repleta de violência física e verbal, resultante da não conformidade de sua forma particular de performar seu gênero. Desventuradamente nascido com uma vulva e destinado a secretar estrogênio ("hormônio feminino", como ele sempre diz, sarcasticamente) em grande quantidade, desde a vida intrauterina foi "lido", por meio da imagem do ultrassom, como uma menina. Quando o médico comunicou a seus pais que se tratava de uma menina, selou seu destino. Os primeiros anos de sua vida seguiram o fluxo heteronormativo tradicional, em que meninas vestiam vestidos cor-de-rosa, tinham suas orelhas perfuradas ainda bebês para colocação de brincos e eram carinhosamente apelidadas de princesas. Jonas pas- sou por todas essas experiências de performação do gênero alinhado ao corpo biológico com uma difusa sensação interior de desajustamento. "Eu não sabia o quê, mas sabia que tinha alguma coisa diferente comigo. Eu não sentia que era errado, mas toda vez que eu falava sobre isso eu levava bronca. Mais do meu pai do que da minha mãe".

Jonas tentava construir-se enquanto ser autônomo desde cedo, recusando-se a usar os vestidos que sua mãe lhe comprava. Chegou a pedir para que sua festa de aniversário de seis anos tivesse como tema o desenho "masculino" Super Patos, mas ganhou uma festinha simples com decoração do Dumbo, uma vez que o famoso elefantinho da Disney era considerado um personagem "neutro": servia tanto para meninos quanto para meninas. Essa foi a forma que seus pais encontraram de equilibrar um "desejo de menino" com uma opção aceitável para uma menina, o que evitaria o estranhamento e possível escracho por parte do restante da família e dos amigos.

Mais do que questionar a obrigatoriedade do binarismo de gênero, Butler questiona a própria ideia de gênero como constructo genético/biológico estável e imutável que acompanha o indivíduo ao longo de sua vida sem sofrer variações. Nesse contexto, propõe a compreensão de que o gênero se localiza no ato e não no constructo. Consoante com esse pressuposto, a autora elabora o conceito de performatividade, inspirado na interpretação que Jacques Derrida elabora acerca da obra de Austin (Porchat, 2014). Butler (2015) estabelece o gênero como um ato/performance em que o indivíduo reproduz efusivamente as significações culturais atribuídas ao seu "gênero de nascimento", de forma a garantir a manutenção do binarismo. Um dos problemas aqui é que, justamente pelo fato de que o gênero não possui qualquer tipo de significação a priori - por exemplo, conferida geneticamente - os corpos não se docilizam frente à performance do sujeito, de forma que ele deve estar sempre performando a fim de garantir a unidade do gênero.

O padrão heteronormativo vigente na cultura na qual Jonas estava inserido, e que era reproduzido nas relações que seus familiares estabeleciam com ele, começava a tentar conter o fluxo criativo de elaboração de sua identidade de gênero (Warner, 1993). O caminho da heterossexualidade e do gênero binário começou a the ser empurrado "goela abaixo" (sic), 
tal como acontece geralmente com os indivíduos, mas que ressoa de forma ainda mais torturante para crianças trans. Porém, de forma distinta da que se observa na maioria dos contextos familiares, seus pais não eram "monstros". Ao contrário, Jonas relata que eles faziam de tudo para entendê-lo e protegê-lo dos ataques do "mundo fora de casa". "Eles sempre foram carinhosos, principalmente minha mãe. Meu pai era mais fechadão, por causa da criação dele, mas ele sempre defendeu eu e minha irmã. É que eles não sabiam como lidar com aquilo".

Os pais de Jonas eram frutos de uma educação coercitiva, que tinha a cultura heteronormativa como principal fonte de (des)informação. Ao normalizar a ideia de que existem apenas duas "categorias" de gênero (homem e mulher) e que o único desejo amoroso/sexual legítimo é aquele voltado para o gênero oposto, a heteronormatividade faz crer que o mundo sempre foi assim e que as identidades pré-fabricadas devem ser incorporadas e mantidas operando a qualquer custo.

Quaisquer atos performáticos que apontem para a desconstrução dessas identidades são imediatamente reprimidos, devido ao caráter abjeto que a tentativa de performar uma identidade diferente do modelo prescrito pode involucrar. A abjeção "[...] relaciona-se a todos os tipos de corpos cujas vidas não são consideradas vidas e cuja materialidade é entendida como não importante" (Butler, 2015, p. 32). Aquilo que é designado como abjeto deve ser descartado para que não contamine os outros. Esse temor de "contaminação" viria a se tornar mais evidente na vida de Jonas quando ele iniciou sua vida escolar.

Já na escola, a identidade de Jonas se mostrava mais evidente para ele à medida que seu corpo de desenvolvia e ele ampliava a consciência de si. Aos 11 anos sua puberdade teve início, juntamente com sua primeira menstruação, um evento vivenciado como "horrível" por ele.

Na primeira vez que sangrou eu meio que sabia o que tava acontecendo, mas uma parte de mim também achou que eu tinha me machucado. Eu tinha jogado bola na escola e quando eu cheguei em casa eu vi a calça manchada, e achei na hora que eu tinha me machucado lá. Eu não falei nada pra ninguém porque fiquei com vergonha, mas quando eu fui tomar banho eu vi que tinha menstruado e não gostei.
Se lidar com o corpo já era difícil, lidar com as reações dos colegas era ainda pior. Na sala de aula era sempre chamado, jocosamente, de "maria-sapatão" devido ao seu jeito "masculino". Os meninos não queriam se aproximar dele porque achavam que era uma "menina estranha" (sic), enquanto que as meninas por vezes eram mais solidárias, mas não criavam vínculos fortes com ele por não reconhecerem em Jonas uma identidade pareável com a delas. O único alento vinha na aula de educação física: Jonas era um ótimo goleiro e por isso era sempre chamado pelos meninos para jogar no time deles. Naquele raro momento em que era escalado para a partida de futebol sua "identidade estranha" (queer) era ofuscada pela identidade de "menina que agarra todas as bolas" (sic).

Embora crianças frequentemente sejam cruéis com aquilo que não entendem, suas identidades estão em ativa construção, sendo esperado que tenham reações de estranhamento frente àquilo com o qual nunca tiveram contato em suas breves vidas. Existe tempo para torná-las mais tolerantes se houver alguém para instruí-las nesse caminho ético. Também é possível fazê-lo nos adultos, mas as resistências são maiores. Jonas não teve essa sorte de encontrar alguém que instruísse seus colegas. Seus professores eram totalmente despreparados para lidar com questões de gênero. Um deles inclusive lhe atormentava com comentários ofensivos, fazendo piadas machistas e "escrotas", em suas palavras. Em um dia específico, incentivado por esse professor, um colega de sala jogou uma cadeira em cima de Jonas. Foi a gota d'água, o "estopim" do sofrimento que o fez abandonar a escola no meio do Ensino Médio. Jonas sempre sentiu que não se adaptava ao ambiente escolar, mas a verdade é que o ambiente nunca o assimilou e acabou por expulsá-lo de suas fileiras. Depois da evasão escolar, provavelmente se instaurou a fantasia de que as identidades de gênero das outras crianças estariam protegidas da ameaça de "contaminação" que ele representava.

Bento (2011) refere-se ao ambiente escolar como um "espaço de reprodução do HeteroTerrorismo" (p. 554). Nesse ambiente crucial para o processo de socialização, todos os mecanismos sociais de controle identitário estão presentes, o que faz com que pessoas trans, homossexuais, lésbicas e bissexuais, por exemplo, sofram tentativa de ajuste identitário. Caso a tentativa falhe (e ela invariavelmente fracassa), essas pessoas são forçadas a se retirar do espaço público e 
excluídas do convívio social. Em casos mais extremos de violência são submetidas a torturas e até mesmo mortas, uma vez que a forma mais fácil de eliminar a "ameaça à identidade heteronormativa" é fazer com que ela desapareça.

Uma vez que a escola se fechou para Jonas, o mercado de trabalho também faria o mesmo. Ele nunca conseguiu um emprego com carteira assinada desde então, sobrevivendo de "bicos" (prestação de serviços intermitentes) até hoje, amargando o subemprego ou nem isso, encargos temporários como segurança de casa noturna, pedreiro, pintor de parede e, por um curto período, ajudante em uma oficina de conserto de bicicletas. Sua dura realidade é infelizmente compartilhada pela maior parcela da população trans no Brasil. Sendo o nível de escolaridade um fator primordial para o ingresso no mercado de trabalho, mesmo que a atividade não exija grande aporte intelectual (Bernardo, 2009), homens e mulheres trans acabam sofrendo um duplo preconceito: primeiro, por suas identidades em não conformidade com o padrão que confere legitimidade aos corpos generificados e, segundo, por sua falta crônica de colocação no mundo do trabalho. Em uma sociedade materialista e de consumo, não produzir é visto como sinônimo de fracasso e invalidismo, e o sentimento de desmoralização pode levar à depressão e ao suicídio (Souza \& Bernardo, 2014).

Justamente nessa parte a história de Jonas encontra seu momento mais grave de queda e, paradoxalmente, seu ponto de virada. Jonas tentou suicídio ingerindo todos os comprimidos de uma caixa de remédio para depressão que ele tomava havia já alguns anos. Por sorte, seu corpo já havia se acostumado com a substância e a reação não foi drástica o bastante para aniquilar sua vida. Ele sobreviveu e começou a frequentar uma organização não governamental (ONG) em sua cidade de origem, que luta pelos direitos LGBT. Nela encontrou conforto, solidariedade e construiu laços sociais com pessoas que tinham histórias parecidas com a sua. Seus pais, a essa altura, já estavam adaptados à sua "condição" (como eles próprios nomeiam). Ele começou a se engajar cada vez mais no ativismo e a militar pelos direitos LGBT. Com isso passou a se munir de conhecimentos jurídicos e médicos para viver e se proteger enquanto homem trans. Atualmente ele coordena um grupo de apoio para pessoas LGBT, cuja sede se localiza em sua própria casa.
Ele conta que, após hesitar por muito tempo, tomou coragem de iniciar um processo de hormonioterapia, sob os cuidados de um ambulatório especializado situado em uma cidade vizinha, para aquisição de características fenotípicas que ele julga importantes para seu processo de aceitação social. No presente momento ele interrompeu o processo devido a algumas complicações clínicas decorrentes do uso contínuo de testosterona exógena.

No meio dessa virada pós-tentativa de suicídio, não se pode deixar de mencionar que Jonas conheceu Ângela, cuja história de menina negra cisgênero a princípio se assemelha a de qualquer outra de sua condição socioeconômica e educacional, porém permeada por particularidades que a levaram ao encontro de Jonas, conforme será examinado a seguir.

\section{Vidas pregressas - Ângela}

Ângela, assim como Jonas, nasceu com uma vulva e um corpo "destinado" a secretar estrogênio em grandes quantidades. Desde o ultrassom, o médico e seus pais sentenciaram que se tratava de uma menina. Os primeiros anos de sua vida seguiram o fluxo heteronormativo tradicional, no qual as meninas são ornamentadas com vestido cor-de-rosa, tem suas orelhas perfuradas ainda bebês para a colocação de brincos e são carinhosamente apelidadas de princesas. Ângela passou por todas essas etapas de reiteração performática do gênero sem qualquer sensação interior de estranheza ou desconforto em relação ao próprio corpo. Pelo menos era o que ela pensava na época.

Ângela provém de uma família muito religiosa, praticante de candomblé, religião de matriz africana que sempre ocupou um lugar crucial em sua vida (hoje em dia Jonas também é adepto dessa religião, graças à influência da companheira). Segundo Ângela, o candomblé foi fundamental para a construção de seu caráter e o modo como ela se entende no mundo. “No candomblé não tem essa de preconceito. Por ser uma religião que foi trazida pelos negros, tem muito negro, mas qualquer pessoa que quiser chegar é bem-vinda. Negro, branco, pobre, rico, gay, trans. Todo mundo pode entrar. Orixá não discrimina".

Apesar de não ter sofrido preconceitos em relação à sua sexualidade e ao seu gênero durante a infância, Ângela - que hoje assume com orgulho sua negritude enquanto matriz de sua identidade - também compõe um subgrupo de identidades abjetas. Ela sofria ocasionalmente na escola com o insulto de 
crianças que diziam que ela tinha "cabelo de bombril", que se estivesse em um lugar escuro ela desapareceria, entre outras "brincadeiras" de cunho ostensivamente racista. Apesar do infortúnio do bullying, ela conta que os pais e os amigos sempre "compensavam" esses problemas, mas que esses embates fizeram com que ela ficasse mais sensível e atenta às "injustiças do mundo" (sic).

Namorou alguns meninos durante sua adolescência e era feliz com isso. Sentia-se plenamente ajustada no plano de suas experiências afetivas, invariavelmente com meninos cisgêneros. Ela diz nunca ter se questionado sobre sua identidade de gênero e sequer sabia o que era isso. E não haveria porque sabê-lo já que ela nunca havia se deparado com um gênero "estranho". Todos os seus namoros estavam chancelados e naturalizados por meio da "heterossexualidade compulsória", tendo sua mente, assim como de tantas outras mulheres cis na sociedade, doutrinada pela ideologia do "romance heterossexual" (Rich, 1980). Para ela, o desejo heterossexual e um futuro casamento eram destinos que não precisavam ser questionados.

O primeiro questionamento só viria quando ela conheceu Jonas.

\section{As histórias se cruzam - Jonas e Ângela}

Jonas e Ângela se conheceram em um barzinho, por intermédio de amigos em comum. Isso aconteceu havia seis anos, em 2013. Jonas ainda não havia iniciado a hormonioterapia, mas performava "como um homem" tão bem quanto podia. Para incrementar sua passabilidade, usava calça jeans, boné, cabelo curto, se sentava com as pernas abertas e falava gírias dos "brothers" (sic).

Ângela sempre foi vaidosa e performava sua feminilidade com esmero. No entanto, ao conhecer Jonas ela sentiu pela primeira vez um estranhamento.

Na hora que eu sentei na mesa com eles eu achei que ele era um menino. Aí depois de um tempo eu olhei e comecei a achar ele meio diferente. Uns traços mais delicados. Mas não tive coragem de perguntar nada. Na hora de ir embora, eu perguntei pra amiga que tinha ido comigo se ele era homem ou mulher. Aí ela disse que ele era mulher, mas achava que era homem. Eu estranhei bastante no começo e fui procurar.
Ao pesquisar sobre o assunto, Ângela ficou curiosa, com desejo de saber mais. Na semana seguinte o grupo de amigos voltou a se encontrar no barzinho e lá estava Jonas. Ela começou a conversar com ele e perguntou um pouco sobre a vida dele, o que ele fazia e aos poucos chegou no assunto da transexualidade. Jonas lhe explicou o que era ser trans e Ângela ficou muito interessada no assunto. No assunto e em Jonas. "Depois disso eu nunca consegui olhar pra ele como mulher. Depois que ele me explicou eu pensei: 'Ah, é um homem'".

Após esse momento eles trocaram os números de telefone e passaram a conversar, até que combinaram de sair e, em pouco menos de um mês, já estavam namorando. Jonas comenta: "Namoro de trans, gay e sapatão é mais rápido. Não precisa ficar de muita conversinha antes de acontecer alguma coisa".

A fala de Jonas refere-se a algo que merece ser discutido. O senso comum tem por hábito reproduzir a ideia de que os relacionamentos LGBT acontecem mais rápido e tendem a ser voláteis, isto é, ter uma duração menor do que os relacionamentos heterossexuais. É sabido que existem de fato algumas diferenças no que tange aos casais LGBT em relação aos casais que estão alinhados à cultura heteronormativa. Um dos fatores de diferenciação está no enrijecimento ou flexibilização dos papéis de gênero. Féres-Carneiro (1997, p. 5), ao abordar os atributos mais valorizados por homens e mulheres heterossexuais e homossexuais na escolha de um parceiro, concluiu que

[...] a competência profissional e capacidade econômica, culturalmente identificados como masculinos, não foram valorizados na escolha de parceiros quando esta era dirigida a mulheres tanto hétero como homossexuais. Assim, a competência profissional foi significativamente mais valorizada pelas mulheres heterossexuais em seus parceiros, do que pelas mulheres homossexuais em suas parceiras.

À medida que "casais heteronormativos" parecem reproduzir com maior frequência papéis de gênero estereotipados, parece haver também uma tendência maior em reiterar outros comportamentos atrelados a esses papéis no que concerne ao relacionamento amoroso. A exemplo disso, ainda persiste, em especial no universo feminino cisgênero, o tabu do sexo no primeiro encontro, tabu atrelado ao ideal 
de pureza feminina, que é fortalecido por culturas que apresentam forte influência judaico-cristã. No que tange às relações lésbicas, essas mulheres que também são portadoras de identidades abjetas e que, de modo similar, porém diferente, estão mais distantes do modelo heterossexual idealizado, essa particularidade parece não ser uma preocupação tão marcada.

Pode-se conjecturar que, quando mais distantes os relacionamentos conjugais estejam da matriz heteronormativa, menos eles tendem a reproduzir suas normas. Isso pode se aplicar às etapas que um relacionamento tende a atravessar. Em relações heterossexuais, persiste uma trajetória mais letárgica entre o primeiro encontro e a relação estável devido a uma série de aspectos morais que medeiam esse relacionamento e que se somam aos mecanismos de estereotipia dos papéis de gênero impostos culturalmente. Já casais LGBT, que em geral estão na contramão de vários desses aspectos, parecem não encontrar tantos obstáculos para concretizar seus relacionamentos, avançando mais rapidamente pelas etapas já mencionadas.

\section{Um futuro que deveria ser possível antever - Jonas e Ângela}

Jonas e Ângela contam que se sentem realizados como casal. A despeito do que se poderia esperar, as famílias de ambos aceitaram bem o relacionamento de ambos. No caso da família de Jonas, houve aceitação imediata de Ângela, que se diz muito amiga de sua sogra. No caso da família de Ângela, ela preferiu ser precavida em relação a Jonas, apresentando-o sem revelar que era um homem trans, por temer um constrangimento da parte de seu pai. Com o tempo, ela falou sobre Jonas com mais calma, adotando a estratégia de mostrar vídeos do Youtube com pessoas trans contanto suas histórias de vida, o que segundo ela ajudou seu pai a entender melhor sobre o assunto. Ela relata que hoje a convivência é tranquila, embora não se toque no assunto da transexualidade em sua casa paterna, o que para ela "é ótimo", já que, em suas palavras, "eu namoro um homem trans sim, mas antes de mais nada eu namoro o Jonas" (sic).

Essa fala mostra que um dos efeitos da passabilidade é inibir a circulação aberta do assunto no espaço público, o que reforça sua invisibilidade social. Quando indagada se sua orientação sexual já havia sido questionada por alguém, Ângela disse que só uma tia distante uma vez perguntou, assustada, se ela tinha virado lésbica. Ela respondeu: "Eu, não! Como eu posso ser lésbica se eu namoro homem?" A tia se calou.

Interessante notar o que acontece quando uma pessoa que supostamente está segura de sua cisgeneridade de repente se vê confrontada em sua certeza quando assume publicamente um relacionamento com uma pessoa trans. Ângela se vê interpelada pela tia a respeito não de sua identidade de gênero, mas de sua orientação sexual. A máxima com que Ângela se defende do ataque homofóbico da tia ("como eu posso ser lésbica se eu namoro homem?") reforça a heteronormatividade como referência de normalidade. Para reiterar sua heterossexualidade perante $o$ olhar de suspeição da tia, ela precisa recorrer ao mais surrado jargão que naturaliza e reifica a divisão binária que regula o sistema sexo/gênero.

No que concerne a serem alvos de preconceitos, Jonas e Ângela relatam que por vezes sentem "olhares diferentes" quando caminham pela rua e que isso os incomoda de alguma forma, mas se sentem privilegiados por nunca terem enfrentado uma situação de maior constrangimento ou de franca violência como a que alguns de seus amigos foram expostos. Eles referiram que a maior força deles vinha do apoio de suas famílias de origem e de seus amigos, os quais reconhecem como parte de sua família também. Jonas pondera que "Quando você é trans, gay, sapatão... você escolhe sua família. Se a pessoa vai gostar de você, ela vai gostar pelo que você é, porque pra não gostar tem um monte de gente por aí. Se a pessoa gosta, é porque você pode confiar".

Sobre o modo como se imaginam no futuro, o casal conta que pretende juntar dinheiro para comprar uma casa própria e deixar de morar de aluguel. Jonas quer arrumar um emprego de carteira assinada para "pelo menos dizer que eu sou o homem [grifo nosso] da casa [risos]". Não ser visto como um cidadão produtivo na sociedade de consumo produz sofrimento por ser entendido como sinônimo de fracasso e incapacidade, suscitando sentimento de desmoralização (Souza, \& Bernardo, 2014). Mas é preciso considerar uma nuance: na sociedade falocêntrica, o impacto subjetivo da não inserção no mercado de trabalho incide de maneira diferente de acordo com o gênero, sendo que para o gênero masculino o desemprego pode ter um efeito mais deletério, no sentido de não poder corresponder a uma prescrição esperada tradicionalmente para o "homem" de ser o provedor material da família. 


\section{Considerações finais}

Com o caso analisado no presente estudo não se tem a intenção de generalizar a experiência da conjugalidade entre pessoas trans e cisgêneras, mas possibilitar que se ilumine, por meio de algumas passagens marcantes, a experiência singular de um casal cis-trans no que tange aos seus esforços para validar sua existência e dignificar suas vidas como vidas que importam, para além da captura do binarismo de gênero e da matriz heteronormativa. Como apresentado, viver e relacionar-se fora das normas culturalmente atribuídas aos gêneros e às sexualidades envolve uma série de riscos, uma vez que nessa condição a vida e o corpo do indivíduo tornam-se abjetos e, como tais, alvos de exclusão e tentativas recorrentes de invisibilização e eliminação do espaço público. Por outro lado, percebeu-se o quanto a boa qualidade do relacionamento conjugal e o apoio recebido de ao menos parte dos familiares atua como elementos estabilizadores no bem-estar psicológico de Ângela e Jonas. Assim, amar para além das normas também pode implicar em um processo de liberdade maior, uma vez que algumas das amarras e limitações próprias da cultura heteronormativa e cis-centrada se afrouxam quando se caminha nas margens dos códigos socialmente sancionados.

O convívio conjugal, quando apoiado pelas famílias do casal e amparado pelos amigos que compõem sua rede pessoal de apoio, tende a agregar fatores favoráveis para o enfrentamento de situações adversas e potencialmente perigosas, que poderiam resultar na dissolução da união ou em ameaça à integridade física por efeito da transfobia. Espera-se que os resultados deste estudo possam fomentar discussões na área acadêmica e em diversos setores da sociedade sobre as múltiplas formas de amar e se relacionar, permitindo um debate mais arejado e que nos leve a uma condição de respeito e aceitação das diferenças. Em especial no Brasil, que no atual momento político encontra-se sob o poder de forças ultraconservadoras que, na intenção de garantir os privilégios de uma suposta maioria, busca sufocar grupos humanos minoritários retirando-lhes direitos e privando-os da condição de humanidade.

\section{Referências}

Alegría, C. A. (2012). Relational and sexual fluidity in females partnered with male-to-female transsexual persons. JournalofPsychiatricandMentalHealthNursing, 20(2), 142-149.https://doi.org/10.1111/j.1365-2850.2011.01863.x

Associação Americana de Psiquiatria - APA. (2014). DSM-V: Manual diagnóstico e estatístico de transtornos mentais (5a ed. rev., C. Dornelles, Trad.). Porto Alegre, RS: Artmed.

Bento, B. (2011). Na escola se aprende que a diferença faz a diferença. Revista Estudos Feministas, 19(2), 549-559. https://doi.org/10.1590/S0104-026X2011000200016

Bento, B., \& Pelúcio, L. (2012). Despatologização do gênero: A politização das identidades abjetas. Revista Estudos Feministas, 20(2), 559-568. https://doi.org/10.1590/S0104-026X2012000200017

Bernardo, M. H. (2009). Discurso flexível, trabalho duro: O contraste entre a vivência de trabalhadores e o discurso de gestão empresarial. São Paulo, SP: Expressão Popular.

Bischof, G. H., Warnaar, B. L., Barajas, M. S., \& Dhaliwal, H. K. (2011). Thematic analysis of the experiences of wives who stay with husbands who transition male-to-female. Michigan Family Review, 15(1), 16-33. https://doi. org/10.3998/mfr.4919087.0015.102

Braun, V., \& Clarke, V. (2006). Using thematic analysis in psychology. Qualitative Research in Psichology, 3(2), 77-101.

Brown, N. R. (2010). The sexual relationships of sexual-minority women partnered with trans-men: A qualitative study. Archives of Sexual Behavior, 39(2), 561-572. https://doi.org/10.1007/s10508-009-9511-9

Butler, J. (2015). Problemas de gênero: Feminismo e subversão da identidade (R. Aguiar, Trad.). Rio de Janeiro, RJ: Civilização Brasileira.

Chetty, S. (1996). The case study method for research in small-and médium-sized firms. International Small Business Journal, 15(1), 73-85. https:// doi.org/10.1177/0266242696151005

Erich, S., Tittsworth, J., Dykes, J., \& Cabuses, C. (2008). Family relationships and their correlations with transsexual well-being. Journal of GLBT Family Studies, 4(4), 419-432. https://doi.org/10.1080/15504280802126141 
Psicologia: Ciência e Profissão 2019 v. 39 (n.spe 3), e228629,75-87.

Féres-Carneiro, T. (1997). A escolha amorosa e interação conjugal na heterossexualidade e na homossexualidade. Psicologia: Reflexão e Crítica, 10(2), 351-368. https://doi.org/10.1590/S0102-79721997000200012

Féres-Carneiro, T. (1998). Casamento contemporâneo: O difícil convívio da individualidade com a conjugalidade. Psicologia: Reflexão e Crítica, 11(2), 379-394. https://doi.org/10.1590/S0102-79721998000200014

Galli, R. A., Vieira, E. M., Giami, A., \& Santos, M. A. (2013). Corpos mutantes, mulheres intrigantes: Transexualidade e cirurgia de redesignação sexual. Psicologia: Teoria e Pesquisa, 29(4), 447-457. https://doi.org/10.1590/S010237722013000400011

Gomez, R. G., Flores, J. G., \& Jiménez, E. G. (1999). Metodología de la investigación cualitativa. Málaga: Aljibe.

Jablonski, B. (2007). O cotidiano do casamento contemporâneo: A difícil e conflitiva divisão de tarefas e responsabilidades entre homens e mulheres. In T. Féres-Carneiro (Org.), Família e casal: Saúde, trabalho e modo de vinculação (pp. 203-228). São Paulo, SP: Casa do Psicólogo.

Kins, E., Hoebeke, P., Heylens, G., Rubers, R., \& Cuypera, G. D. (2008). The female-to-male transsexual and his female partner versus the tradicional couple: A comparison. Journal of Sex \& Marital Therapy, 34(5), 429-438. https://doi.org/10.1080/00926230802156236.

Kulick, D. (2008). Travesti: Prostituição, sexo, gênero e cultura no Brasil (C. Gordon, \& E. R. Hatugai, Trads.). Rio de Janeiro, RJ: Fiocruz.

Lipovetsky, G. (2004). Os tempos hipermodernos (M. Vilela, Trad.). São Paulo, SP: Barcarolla.

Lomando, E., \& Nardi, H. C. (2013). Conjugalidades múltiplas nas travestilidades e transexualidades: Uma revisão a partir da abordagem sistêmica e da psicologia social. Saúde em Debate, 37(9), 493-503. https://doi.org/10.1590/ S0103-11042013000300013

Melo, K. M. M. (2016). Terapia ocupacional social, pessoas trans e teoria queer: (Re)pensando concepções normativas baseadas no gênero e na sexualidade. Cadernos de Terapia Ocupacional, 24(1), 215-223. https://doi. org/10.4322/0104-4931.ctoARF0645

Mosmann, C. P., Lomando, E., \&Wagner, A. (2010). Coesão e adaptabilidade conjugal em homens e mulheres hétero e homossexuais. Barbarói, (33), 135-152.

Muylaert, C. J., Sarubim, V., Jr., Gallo, P. R., Rolim, M. L., Rolim Neto, \& Reis, A. O. A. (2014). Entrevistas narrativas: Um importante recurso em pesquisa qualitativa. Revista da Escola de Enfermagem da USP, 48(2), 193-199. https://doi.org/10.1590/S0080-623420140000800027

Oltramani, L. C. (2009). Amor e conjugalidade na contemporaneidade: Uma revisão de literatura. Psicologia em Estudo (Maringá), 14(4), 669-677. https://doi.org/10.1590/S1413-73722009000400007

Organização Mundial da Saúde - OMS. (1993). Classificação de transtornos mentais e de comportamento: CID-10. Porto Alegre, RS: Artes Médicas.

Porchat, P. (2014). Psicanálise e transexualismo. Curitiba, PR: Juruá.

Rich, A. (1980). Compulsory heterosexuality and lesbian existence. In A. Rich, Blood, bread, and poetry: Selected prose 1979-1985 (pp. 65-87). New York, NY: Norton. Santos, M. A., Souza, R. S., Lara, L. A. S., Risk, E. N., Oliveira, W. A., Alexandre, V., \& Oliveira-Cardoso, E. A. (2019). Transexualidade, ordem médica e política de saúde: Controle normativo do processo transexualizador no Brasil. Estudos Interdisciplinares em Psicologia, 10(1), 3-19. https://doi.org/10.5433/2236-6407.2019v10n1p03

Scorsolini-Comin, F, \& Santos, M. A. (2012). Correlations between subjective well-being, dyadic adjustment and marital satisfaction in brazilian married people. The Spanish Journal of Psychology, 15(1), 166-176. https://doi. org/10.5209/rev_SJOP.2012.v15.n1.37304

Serrano, G. (2004). Investigación cualitativa: Retos e interrogantes. Madrid: La Muralla.

Silva, L. A., Scorsolini-Comin, F, \& Santos, M. A. (2017). Casamentos de longa duração: Recursos pessoais como estratégias de manutenção do laço conjugal. Psico-USF, 22(2), 323-335. https://doi.org/10.1590/141382712017220211

Souza, H. A., \& Bernardo, M. H. (2014). Transexualidade: As consequências do preconceito escolar para a vida profissional. Bagoas: Estudos Gays: Gênero e Sexualidade, 8(11), 157-175.

Warner, M. (1993). Fear of a queer planet: Queer politics and social theory. Minneapolis, MN: University of Minnesota. 
Yin, R. K. (2013). Case study research: Desing and methods (5a ed.). London: Sage.

Zacks, E., Green, R. J., \& Marrow, J. (1988). Comparing lesbian and heterossexual couples on the circumplex model: An initial investigation. Family Process, 27(1), 471-484. https://doi.org/10.1111/j.1545-5300.1988.00471.x

Zordan, E. P., \& Wagner, A. (2009). Projetos vitais de adultos jovens solteiros: Uma reflexão sobre o lugar do casamento. Contextos Clínicos, 2(2), 91-96.

\section{Vinícius Alexandre}

Psicólogo, Mestrando pelo Programa de Pós-Graduação em Psicologia da Faculdade de Filosofia, Ciências e Letras de Ribeirão Preto da Universidade de São Paulo (USP), Ribeirão Preto - SP. Brasil.

E-mail: valexandre83@gmail.com

(iD https:// orcid.org/0000-0003-0275-9320

\section{Manoel Antônio dos Santos}

Psicólogo. Professor Titular da Faculdade de Filosofia, Ciências e Letras de Ribeirão Preto da Universidade de São Paulo (USP), Ribeirão Preto - SP. Brasil.

E-mail: masantos@ffclrp.usp.br

(iD) https:// orcid.org/0000-0001-8214-7767

Endereço para envio de correspondência:

Faculdade de Filosofia, Ciências e Letras de Ribeirão Preto, Universidade de São Paulo (USP). Av. Bandeirantes, 3900, Monte Alegre, Campus Universitário. CEP: 14040-901 - Ribeirão Preto - SP, Brasil.

Recebido 12/09/2019

Aceito 04/10/2019

Received 09/12/2019

Approved 10/04/2019

Recibido 12/09/2019

Aceptado 04/10/2019

Agradecimentos:

Coordenação de Aperfeiçoamento de Pessoal de Nível Superior - CAPES (processo número 134357/2018-3) e

Conselho Nacional de Desenvolvimento Científico e Tecnológico - CNPq.

Como citar: Alexandre, V. \& Santos, M. A. (2019). Experiência Conjugal de Casal Cis-trans:

Contribuições ao Estudo da Transconjugalidade. Revista Ciência e Profissão, 39 (n.spe 3), 75-87.

https://doi.org/10.1590/1982-3703003228629

How to cite: Alexandre, V. \& Santos, M. A. (2019). Marital Experience of a Cisgender-Transsexual

Couple: Contributions to the Study of Transconjugality. Revista Ciência e Profissão, 39 (n.spe 3), 75-87.

https://doi.org/10.1590/1982-3703003228629

Cómo citar: Alexandre, V. \& Santos, M. A. (2019). Experiencia Marital de la Pareja Cisgénero-Transexual:

Contribuciones al Estudio de la Transconjugalidad. Revista Ciência e Profissão, 39 (n.spe 3), 75-87.

https://doi.org/10.1590/1982-3703003228629 